\title{
Who Bets on Sports? Characteristics of Sports Bettors and the Consequences of Expanding Sports Betting Opportunities*
}

\author{
BRAD R. HUMPHREYS \\ Department of Economics, UNIVERSITY OF ALBERTA, CANADA. E-mail: \\ bhumphre@ualberta.ca

\section{LEVI PEREZ} \\ Departamento de Economía, UNIVERSIDAD DE OVIEDO, Fundación Observatorio \\ Económico del Deporte,ESPAÑA.E-mail: lperez@uniovi.es
}

\begin{abstract}
Currently, several proposed changes in sports betting laws are being debated in the United States and the European Union. This article examines the characteristics of sports bettors in three countries, Canada, Spain, and the United Kingdom, to determine who bets on sports in environments where this activity is both legal and popular. Unconditional and conditional analyses find that annual participation rates in sport betting are low, and that sport bettors tend to be young males with relatively high incomes. Sports bettors stand to gain the most from an expansion of legal sports betting opportunities, while the negative impacts of increased access to sports betting are expected to be minimal in the United States and difficult to assess in the European Union.
\end{abstract}

Keywords: Sport Betting, Gambling, Regulation, Opportunities.

\section{¿Quién apuesta? Características de los apostantes deportivos y consecuencias de la expansión de las oportunidades de apostar}

\begin{abstract}
RESUMEN
Actualmente, un importante número de cambios en la legislación del mercado de apuestas deportivas están siendo debatidos tanto en Estados Unidos como en la Unión Europea. En este artículo se examinan las características socioeconómicas de los apostantes deportivos en Canadá, España y el Reino Unido con el objeto de determinar el perfil de estos jugadores en contextos donde está actividad es legal y muy popular. El análisis empírico muestra que la frecuencia de participación en este mercado es baja y que el perfil de los apostantes tiende a ser el de un hombre joven con ingresos relativamente altos. Se concluye que los propios apostantes serían los potenciales beneficiarios de una expansión de las oportunidades de apostar, mientras que el impacto negativo de esta liberalización se espera sea mínimo en Estados Unidos y difícil de calcular en la Unión Europea.
\end{abstract}

Palabras clave: Apuestas deportivas, regulación del juego, oportunidades.

JEL Clasification: D12, K29, K42, L83

\footnotetext{
* Both authors are thankful for valuable comments by two anonymous referees. Perez acknowledges the financial assistance of the Loterías y Apuestas del Estado for this research and also wish to express his gratitude for financial support from grant ECO2008-06395-C05-01. Humphreys acknowledges the financial assistance of the Alberta Gaming Research Institute and the Loterías y Apuestas del Estado for this research.
}

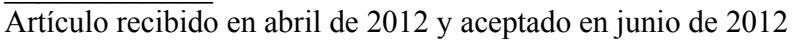

Artículo disponible en versión electrónica en la página www.revista-eea.net, ref. ə-30211 


\section{INTRODUCTION}

Gambling on sporting events is a popular activity among consumers that is also viewed with either skepticism or outright hostility by both government and many sports leagues. Despite the opposition, some form of legal sports betting exists in almost every country, and anecdotal evidence indicates widespread informal betting on sports. Significant demand for sports betting among consumers clearly exists. While betting on informal athletic events like footraces could take place in the absence of organized sporting events, the existence of a large number of highly organized team sports leagues and individual sports associations enhances betting opportunities by providing a regular schedule of events to bet on, and a widely accepted and rigidly enforced set of rules of play. Yet most professional and amateur sports organizations and associations actively oppose any form of betting on the events that they organize and sponsor. For example, in the United States (US), the National Intercollegiate Athletic Association's (NCAA) official policy is to oppose all forms of legal and illegal betting on sports; the National Football League (NFL) formally opposed the recent legalization of sports betting in the U.S. state Delaware. Professional and amateur sports organizations typically cite the corrupting influence of sports betting on athletes and events when opposing sports betting.

Governments hold divergent positions on sports betting. Legal sports betting exists in four US states: Nevada, Oregon, Montana and Delaware. However, the US government passed a law, the Professional and Amateur Sports Protection Act (PASPA), in 1992 that explicitly outlaws sports betting in all but these four states. A form of legal sports betting, where bets must be placed on two or more games at the same time, exists in Canada. In Spain, the sports betting industry was ran as a state monopoly for several years and only few regions allowed bookmakers to operate. Nevertheless, even though there was no specific regulation for online gambling, most of the principal international operators were actively present in the country. Many other countries in other parts of the world allow unlimited sports betting and often actively encourage sports betting by operating nationwide monopoly sports betting operations, often in conjunction with national lotteries. In general, governments appear to trade off the negative aspects of sports betting and the revenues that can be gained by regulating and taxing this activity.

Several recent events related to the supply of sports betting opportunities motivate this paper. In 2005 the Oregon legislature voted to eliminate a longrunning sports betting game operated by the Oregon Lottery, Sports Action. This sports betting game was quite profitable, earning about $\$ 12$ million in its final year of operation, but was eliminated because of continuing pressure from the NCAA, which threatened to ban Oregon from hosting NCAA postseason events if it did not eliminate this game. In June 2009 the state of Delaware 
passed a law making sports betting legal in the state. Some form of sports betting, either Nevada-style bookmaking or an Oregon-style lottery based sports betting game will soon be available in Delaware. Immediately following the legalization of sports betting in Delaware, the governor of neighboring New Jersey announced an initiative to legalize sports betting in that state, citing the potential for sports betting in Delaware to reduce gambling revenues in New Jersey. Also in 2009, the state of Montana announced that it would expand its current NASCAR-based sports betting game to NFL games at the start of the upcoming football season. In Europe, the European Union (EU) has been taking aggressive actions to eliminate state-run monopoly sports betting operations in EU countries in order to open up domestic sports betting to more competition. This change opens up the possibility of legal internet sports betting as well as widespread sports book making like what currently exists in the United Kingdom (UK) in all countries in the EU. Italy has developed a new regulation of internet gambling, France is currently crafting new gambling regulations in response to EU rulings, Spain recently passed a new gambling law, including, for the first time, online sport betting regulation, and the EU has sent requests for details on current gambling regulations to Germany and Sweden. The new Spanish gaming law specifically regulates the activity of sports betting provided from Spain or from other countries as long as aimed to Spanish residents. It also regulates the advertising, promotion and sponsoring of this activity.

Finally, the growing availability of internet sports betting sites calls into question the ability of governments to regulate sports betting. In 2006 the US passed a law, the Unlawful Internet Gambling Enforcement Act (UIEGA), making transactions between US financial institutions like banks and credit card companies and on-line gambling sites illegal. Following the passage of UIEGA, a number of prominent on-line gambling operators like Bwin and Sportingbet ceased commercial transactions with US customers. UIEGA also led directly to a trade dispute between the US and Caribbean nation of Antigua and Barbuda over the provision of internet gambling services that was heard by the World Trade Organization and resulted in sanctions leveled against the US for restraint of trade. However, internet gambling continues to expand, especially in the EU, and there have been continuing calls for repeal of this US law. In the case of Spain there were no specific laws that regulate online gambling. However, a few years ago, the Spanish government began moving towards the the regulation and legalization of internet gambling. Nowadays, betting on sports can be performed via physical presence or electronic means and the first licenses will be soon available to EU operators. As internet sports betting opportunities expand, it will be increasingly difficult to regulate sports betting around the world.

All these events affect sports bettors in some way. The current ban on sports betting in the US, outside of Nevada, Delaware, and Nevada, also has an impact on consumers who would like to bet on sports but cannot under the current 
regulatory environment. In Spain, the development of the Spanish Gaming Law 13/2011 leads players to have a full range of Sports betting opportunities. Since the ultimate cost of sports betting regulation falls on bettors, we examine the characteristics of sports bettors in three countries, Canada, Spain, and the UK, where sport betting is legal and widely available. We focus on these three countries because surveys of sports bettors have recently been conducted there, we have access to these surveys, and the questions asked in these surveys are relatively comparable. This allows us to develop evidence about the characteristics of sports bettors in these three countries and compare the characteristics of sports bettors across the countries. We also discuss the current availability of sports betting in the US and develop some evidence about the characteristics of US sports bettors.

Given this information about the characteristics of sports bettors, we assess the likely impacts of an expansion of sports betting opportunities in both the US and the EU. An improved understanding of the characteristics of sports bettors and the potential consequences of an expansion of betting opportunities will help policy makers understand the likely consequences of changes in existing sports betting regulations and enhance understanding of the costs and benefits of existing sports betting regulations.

\section{THE AVAILABILITY OF LEGAL SPORTS BETTING}

The availability of sports betting in any economy depends on both the regulations put in place by the government and the willingness of some individuals to violate these regulations. Simmons (2008) provides a thorough analysis of the factors that influence the amount of regulation placed on gambling opportunities. Simmons (2008) stresses the inherent tension between consumers who view gambling as entertainment and governments who view state sponsored monopoly gambling industries as an important source of revenue as an important determinant of the amount of legal gambling available in an economy.

Sauer (2001) explains the regulation and availability of gambling in the context of a public choice model. In this model, governments set regulations in response to lobbying by interest groups, and society contains a pro-gambling component whose welfare rises with gambling availability and falls with gambling regulation and an anti-gambling group which wants to restrict gambling opportunities. The anti-gambling group contains individuals and organizations like churches that dislike gambling for a number of reasons. In the case of sports betting, this group can also contain professional and amateur sports organizations like the NCAA. The Gambling regulations that emerge from this model are a function of the relative effort that the two groups place on lobbying. Simmons (2008) points out that this model cannot be applied to settings where significant gambling opportunities already exist. 
Forrest and Simmons (2003) analyze the economic and public policy context of sports betting. They document the rapid growth in sports betting in the past few decades and discuss the potential for this increase to generate revenues for both governments and sports organizations. Forrest and Simmons (2003) also discuss negative aspects of sports betting, including the incentives for corruption it generates. Forrest and Simmons (2003) emphasize the symbiotic nature of the relationship between sport and sports betting and point out the importance of complementarities between sport spectating and sports betting as well as the tensions generated by this symbiotic relationship. The importance of complementarities in consumption drives demand for sports betting and puts pressure on governments to expand sports betting opportunities while the corruptive factors fuel the desires of anti-sports gambling groups and leads to increased pressure to restrict sports betting opportunities.

García and Rodríguez (2007) and García et al. (2008) demonstrate the existence of important complementarities between sport spectating and sports betting in Spain. Although no formal evidence of such complementarities exists in other countries, we assume that these benefits are general, and also exist in Canada and the UK.

All of the factors described above are at work to some extent in the three sports betting markets we examine in this paper. Clearly, the sports betting market in the US is in a state of transition, with important increases and decreases in sports betting opportunities occurring frequently across the country. Below, we describe the sports betting opportunities that exist in the three countries we have detailed data on sports betting market participation for, Canada, Spain, and the UK, and also describe the current sports betting opportunities in the US.

\subsection{Sports betting in Canada}

Canadians can bet on sporting events through a group of lottery based games referred to collectively as Sports Select. Sport Select includes a number of similar sports betting lottery games offered by groups of Canadian provinces. The games included under the Sports Select umbrella include Pari sportif, ProLine, and Sports Action. In some provinces in Western Canada, Point Spread, a lottery based game featuring bets against point spreads is also offered. All of these sports lottery tickets can be purchased at lottery outlets across Canada. In some provinces, Sports Select tickets can be purchased on the internet. The Sports Line games, with the exception of Point Spread, are all based on fixed odds bets on outcomes and totals in professional and amateur sporting events, including games in the major North American sports leagues, US college football and basketball games, and PGA tour tournaments. The Sports Select games 
are parlay games where bettors must pick the outcome of between two and twelve sports events.

Payouts in Sports Select are not pari-mutuel. Instead, the lottery corporations make profits based on overround, the amount by which the win probabilities implied by the fixed odds offered on specific outcomes exceed 100. The overround on Sports Select bets varies depending on the number of events selected. The minimum overround is $160 \%$, and it can be over $300 \%$ depending on the exact set of events selected. Payouts are capped at $\$ 2,000,000$ per card no matter how large the odds on the selected events.

\subsection{Sports betting in Spain}

The Spanish State Lotteries and Gaming, a government organization reporting to the Ministry of the Finance and Public Administration, controls all legal sports betting in Spain. Sport betting consists of pools and other competitions for forecasting the results of sports events. Despite Spain's enthusiasm for football, legal sports betting was largely limited to people gambling on the outcome of professional football matches through football pools. However, several bookmakers were awarded the first licenses to operate sports betting in both the Basque Country and Madrid at the beginning of 2008. Later, other Spanish regions including Aragon and Valencia, among others, join this practice and regulate the activity of betting, opening up a completely new sports betting market. Apart from these betting outlets it should be noted that online gambling in Spain is now legal, so Spaniards can readily betting on sports in the internet. However, the legislative changes to Spain's online gambling laws are even being developed and the liberalization of this market in Spain is still in progress. Other legal forms of sport betting in Spain include horse and dog racetrack betting and gambling on the Basque ball game jai-alai. We examine only football pools because of a lack of data on other types of sport betting and the size of these markets relative to football pools.

Football pools (La Quiniela) were introduced in Spain in the 1946-47 season and they have long occupied an important place in the Spanish gambling market. In 2006 La Quiniela turnover (total sales) was over $€ 480 \mathrm{~m}$, about $€ 10.89$ per inhabitant. Furthermore, the exceptional importance of this gambling industry in Spain lies in the scope of its economic and social benefits; generally speaking, the funds obtained have the objective of promoting sports activities. A Spanish Royal Decree of February 20, 1998, established the current distribution of football pools revenues. The Spanish Professional Football League $(L F P)$ receives $10 \%$, the National Council of Sports gets $1 \%$, and $10.98 \%$ goes to the provincial governments in order to promote social activities and sport facilities. The Public Exchequer takes in $23 \%$ of total revenues, once the ad- 
ministration and distribution expenses have been discounted. The takeout rate on football pools is $45 \%$, and payouts are pari-mutuel.

This state-operated football pools is managed by a public institution, Loterías y Apuestas del Estado (LAE), which is also responsible for operating the National Lottery (a passive lottery game), several high payout, low odds lotto games and some lottery-type games related to horse racing. Tickets cost $€ 0.5$ and they can be bought at any of the local state lottery shops widely available throughout Spain. Each bet is composed of 15 matches corresponding, in general, to Spanish First and Second Division teams. Players have the possibility of choosing the final result of each match from among three alternatives: home win (1), draw (X) and away win (2). To win the maximum prize players must correctly guess the results of all 15 matches included in the coupon. Lower prizes are awarded to those correctly guessing $10,11,12,13$ or 14 results. There are facilities on the form for multiple forecasts, but this may be complicated and is expensive. If the main prize is not won, it is rolled over to the following week.

La Quiniela is only offered during the Spanish football season, unlike the UK where Australian games are included in football pools in summer. Players can ask for a lucky dip, but there is a 2 column minimum entry fee of $€ 1$ for this bet. It is common to play football pools as part of a syndicate, where large groups of bettors (peñas) combine funds and knowledge to bet on football pools.

\subsection{Sports betting in the United Kingdom}

The UK has among the most developed sports betting markets in the world. Bookmaking is a legal, regulated industry in the UK and prominent private bookmakers like Ladbrokes and Betfred operate hundreds of betting shops across the UK where bettors can place fixed odds bets on sporting events. Fixed odds sports betting in the UK is not pari-mutuel and does not involve any takeout; UK bookmakers earn profits by setting betting odds such that an equal amount wagered on each possible outcome (a win, loss or tie in football games or a win or a loss in other sporting events) would result in a loss to the bettor. Setting fixed odds in this way is called overround; the typical overround in fixed odds betting on football games in the UK is about ten percent. UK bookmakers also take bets on sporting events over the internet.

Football pool betting, a form of sports betting based on correctly forecasting the outcome in a number of football games, is also legal and very popular in the UK. A number of private companies, including Littlewoods and Vernons, operate football pools in the UK. Football pool operators take entries over the internet. 


\subsection{Sports betting in the United States}

Currently, betting on individual sports events is only legal in the state of $\mathrm{Ne}-$ vada in the United States. Casinos in Atlantic City, New Jersey are not permitted to operate sports books. Sports books in Nevada offer points spread and fixed odds betting on all types of professional and amateur sporting events. The standard bet on a sporting event in Nevada follows a "wager 11 to win 10" format where a bettor must risk $\$ 110$ to win $\$ 100$. The ten percent commission on these bets is often called the "vig" or "juice." Anecdotal evidence suggests that quite a bit of illegal sports betting takes place in the US. Strumpf (2003) analyzed the behaviour of several illegal sports book makers in New York City.

From 1987 until 2007, the Oregon Lottery operated Sports Action, an NFL sports betting lottery game similar to the Sports Select game offered in Canada and the La Quiniela game offered in Spain. Sports Action tickets could be purchased at Oregon Lottery outlets. Players could pick against the spread, on totals, or on other special events like the number of sacks or fumbles in a football game. A minimum of three games or special events had to be selected on each ticket, and a maximum of 14 could be selected. Players could wager between $\$ 2$ and $\$ 20$. Payouts were pari-mutuel; the minimum payout for correctly picking 3 out of 3 games was $\$ 10$ on a $\$ 2$ ticket and $\$ 20$ on a $\$ 2$ ticket for correctly picking 4 out of 4 games. If there was no winner in a category ( 3 picks, 4 picks, etc.), the dollars bet rolled over to the next week's game. The takeout rate on Sports Action was $40 \%$.

The Montana Lottery currently offers a lottery based sports betting game based on NASCAR automobile racing. Called Fantasy Auto-Racing, this game is effectively a NACSAR parlay bet. Bettors select five drivers participating in each week's NASCAR race and winners are determined by the number of points earned by the five drivers selected. Bettors can wager between $\$ 5$ and $\$ 100$ per ticket. Payouts are pari-mutuel, and the takeout rate is $26 \%$. The Montana Lottery plans to offer a football betting lottery in fall 2009.

\section{DATA AND EMPIRICAL ANALYSIS}

We analyze the behaviour of sports bettors in Canada, Spain, and the UK using data from three recently conducted surveys of gambling behaviour from each country. These surveys contain relatively similar questions about sports betting as well as questions about the economic and demographic characteristics of respondents.

The Canadian data come from a 2002 survey of gambling prevalence in the province of Alberta. While this survey is not nationally representative, it is representative of the adult population of Alberta, a province with a population of over 3 million, the fourth largest Canadian province. These data were col- 
lected through a random digit dial (RDD) telephone survey administered by the University of Alberta Population Research Laboratory. The survey was conducted in the summer of 2002 and 1,804 households participated in the survey. One person from each household was contacted; questions about all members of the household were answered by this individual.

The Spanish data come from two computer assisted RDD telephone interview surveys administered by LAE, the Spanish state lottery agency, in 2005 and 2006. Both surveys included a random sample of all adult residents of Spain. The first survey took place in the spring of 2005, the second in the summer of 2006. A number of 1,412 households participated in the first survey and 1,205 households participated in the second survey. Although a large number of identical questions appeared on both, there were a few differences between the two surveys. The exact age of the head of the household was available in the first survey but only age intervals were available in the second. We recoded each age interval variable at the midpoint of the range for the second survey. Also, monthly income data were collected by income range, and we recoded the income variable reported for each respondent at the midpoint of the range.

The UK data come from "Taking Part: The National Survey of Culture, Leisure and Sport" a nationally representative survey of the adult population of England conducted in late 2005 and early 2006 by BMRB Social Research for the Department for Culture, Media and Sport. These data were collected during a face-to-face interview lasting 35 minutes on average. Just over 26,000 households participated in the survey. In addition to questions on gambling, this survey contained detailed questions on sport participation and participation in cultural activities like attending concerts, museums, and historical sites.

All three surveys contained questions about participation in sports betting. Although the types of questions differed, the key point is that all three surveys allow us to identify people who have bet on sporting events in the past. In addition, residents of all three countries have easy access to sports betting opportunities. In Canada and Spain, sports betting games are offered by monopoly lottery companies that operate a large number of retail outlets and advertise heavily on TV and radio, and in print media. In the UK, private bookmakers operate thousands of betting shops all over the country. In addition, bookmakers and football pool operators take bets and entries over the internet. Access to legal sports betting opportunities should not be a problem for potential sports bettors in these three countries.

\subsection{Characteristics of sports bettors}

Table 1 summarizes the estimated participation rates in sports betting markets, and frequency of sports betting in the three analyzed countries. The UK survey contained questions about sports betting, including fixed odds betting on 
events like football matches and participation in football pools, in the last week and the last year. The Spanish survey asked only about lifetime participation in La Quiniela, the Spanish pari-mutuel betting game on football matches. The Canadian survey asked questions about participation in Sport Select, the sports betting game operated by the Western Canada Lottery Corporation in Alberta over the past year.

Table 1

Estimated sports betting participation and frequency

\begin{tabular}{|l|c|c|c|}
\hline & Canada & Spain & UK \\
\hline Weekly Participation Rate & - & - & 2.22 \\
\hline Annual Participation Rate & 3.10 & - & 5.15 \\
\hline Lifetime Participation Rate & - & 49.75 & - \\
\hline & & & \\
\hline Participates Weekly & 29.63 & 19.70 & - \\
\hline Participates Monthly & 22.22 & 11.33 & - \\
\hline Participates Less Frequently & 48.15 & 68.97 & - \\
\hline
\end{tabular}

Source: Own elaboration based on data from the three cited surveys of gambling behaviour.

Participation in sports betting markets is quite high in Spain. Almost half of the adult population of Spain has purchased a La Quiniela ticket in their lifetime. The estimated participation rates in sports betting markets are much lower in Canada and the UK. Part of this difference can be explained by the time frame of the participation question. Even if most sports bettors only bet infrequently, lifetime participation rates must be higher than annual or weekly participation rates. However, the effective price of making a bet on a sporting event also plays a role in determining participation rates in sports betting markets. In the UK, a bettor can place a fixed odds bet on an individual football match, or other sporting event, with any one of the numerous private book makers operating in that market. The UK is the only market where a bet can be placed on an individual game or match. In Alberta, a bettor must bet on a minimum of two sporting events and place the bet with the government operated lottery corporation; in Spain, buyers of a La Quiniela ticket must predict the outcome of multiple football matches. The effective cost of a bet also differs due to takeout and overround in each market. ${ }^{1}$ Canadian sports bettors face overround

\footnotetext{
${ }^{1}$ Overround refers to the potential profit made by bookmakers in fixed odds betting markets. The odds on the outcome of a sporting event like a football game are quoted for three outcomes: home win, draw, and away win. A bookmaker aims to accept bets on the outcome of these events in the right proportions so that he makes a profit regardless of which outcome come out. So, bookmakers set the odds in such a way that by adding the probabilities together a total of
} 
of anywhere from $160 \%$ to $300 \%$, while English bettors face an overround of only about $110 \%$. The difference can be attributed to the amount of competition in the sports betting markets. This difference probably contributes to the lower sports betting market participation rate in Canada. There is no overround in $L a$ Quiniela, but the takeout rate in this game is $45 \%$.

The Spanish and Canadian surveys also asked questions about the frequency of participation among participants. The bottom panel of Table 1 summarizes these responses for sports bettors. In Canada about half of the sports bettors bet at least monthly; in Spain just less than one third of the bettors bet at least monthly and the rest bet less frequently. The large number of infrequent participants in sports betting in Spain helps to explain the high lifetime participation rate reported on Table 1. Infrequent participants only bet on sports occasionally, or may have only bet on sports on a handful of occasions. Many of these individuals would not report betting on sports in the last year because of the sporadic nature of their participation. But infrequent participants would answer yes if asked if they had ever bet on sports, even if they only be on sports one time years ago. The time frame of the questions, coupled with infrequent participation by a large segment of the population, can explain the large differences in reported participation rates.

All three surveys contain detailed demographic and socioeconomic information about respondents. Table 2 summarizes some of the characteristics of sports bettors in these three countries. This table shows the sample averages for gamblers and non-gamblers and the overall sample average for all three surveys. The column headed "t-test p-value" is the p-value at which the null hypothesis that the two means are equal would be rejected. For small values of this pvalue, the average for gamblers is statistically different from the average for non-gamblers.

Canadian sports bettors tended to be younger than average and English sports bettors older. The income variables were household income in all three cases, and the reported figures have been converted to 2006 US dollars using the Purchasing Power Parity exchange rate estimates published by the Organization for the Economic Co-operation and Development (OECD). Canadian sports bettors had the highest income and Spanish sports bettors the lowest. The estimated average household income of sports bettors in the UK is roughly equal to the median household income in the UK; the estimated average household income of Canadian sports bettors is well above the median household income in Canada and more than double the median household disposable income in Spain $€ 13,714$.

more than $100 \%$ would be achieved. The amount exceeding $100 \%$ is known as the overround. It is equivalent to a commission. 
Table 2

Characteristics of sports bettors

\begin{tabular}{|c|c|c|c|c|}
\hline & Non Bettors & Bettors & Total & t-test $p$-value \\
\hline \multicolumn{5}{|l|}{ CANADA } \\
\hline Age & 43.60 & 33.80 & 43.30 & $<0.001$ \\
\hline Income $(000)$ & 56.59 & 64.87 & 56.88 & 0.177 \\
\hline Male & 0.49 & 0.88 & 0.50 & $<0.001$ \\
\hline Single & 0.21 & 0.41 & 0.21 & 0.003 \\
\hline College Education & 0.45 & 0.45 & 0.45 & 0.962 \\
\hline Employed & 0.69 & 0.77 & 0.69 & 0.217 \\
\hline Persons in Household & 2.43 & 2.20 & 2.42 & 0.178 \\
\hline \multicolumn{5}{|l|}{ SPAIN } \\
\hline Age & 48.30 & 43.20 & 45.80 & $<0.001$ \\
\hline Income $(000)$ & 17.17 & 20.65 & 18.92 & $<0.001$ \\
\hline Male & 0.35 & 0.60 & 0.48 & $<0.001$ \\
\hline Single & 0.15 & 0.10 & 0.13 & 0.001 \\
\hline College Education & 0.48 & 0.56 & 0.52 & $<0.001$ \\
\hline Employed & 0.61 & 0.71 & 0.66 & $<0.001$ \\
\hline Persons in Household & 2.90 & 3.10 & 3.00 & $<0.001$ \\
\hline \multicolumn{5}{|l|}{ UK } \\
\hline Age & 48.80 & 43.90 & 48.60 & $<0.001$ \\
\hline Income $(000)$ & 16.44 & 21.34 & 16.71 & $<0.001$ \\
\hline Male & 0.43 & 0.79 & 0.45 & $<0.001$ \\
\hline Single & 0.28 & 0.38 & 0.28 & $<0.001$ \\
\hline College Education & 0.30 & 0.29 & 0.30 & 0.607 \\
\hline Employed & 0.53 & 0.69 & 0.54 & $<0.001$ \\
\hline Persons in Household & 2.48 & 2.50 & 2.48 & 0.559 \\
\hline
\end{tabular}

Source: Own elaboration based on data from the three cited surveys of gambling behaviour.

Sports bettors in all three countries tend to be male and employed. They also tend to be not single. The other martial status categories include married, cohabitating, divorced and widowed. The level of education of sports bettors varies widely across the three countries. Sports bettors in the UK tend to be less educated; only $29 \%$ of them attended college. Sports bettors in Canada and Spain tend to have more education, with Spanish sports bettors having the highest college attendance rate.

\subsection{Conditional analysis of sports betting market participation}

The unconditional statistics discussed above provide important information about the characteristics of sports bettors in Canada, Spain and the UK. However, a conditional analysis of the factors that explain observed variation in 
sports betting market participation can also uncover important features about consumer behaviour in these markets.

Our conditional analysis of consumer participation in sports betting markets is based on a probit model. Consider a latent variable $\mathrm{Y}^{*}$ that reflects the net utility that an individual gets from betting on a sporting event. $\mathrm{Y}^{*}$ is determined by characteristics of the individual and the sports betting market that the individual can participate in and a random variable capturing other factors that affect the utility derived from betting on sporting events

$$
Y_{i}^{*}=\beta X_{i}+e_{i}
$$

where $X_{i}$ is a vector of individual and market characteristics, $\beta$ is a vector of unknown parameters, and $e_{i}$ is a mean zero constant variance random variable that captures all other unobservable factors that affect the utility individual $i$ receives from sports betting. If $Y_{i}^{*}>0$ the individual bets on sports and if $Y^{*}{ }_{i}=<0$ he individual does not. Define an indicator variable $Y_{i}$ that is equal to one if individual $i$ is a sports bettor and equal to zero if individual $i$ is not a sports bettor. The unknown parameters in equation (1) can be estimated by the standard probit estimator

$$
P\left[Y_{i}=1 \mid X_{i}=x_{i}\right]=\Phi\left(\beta X_{i}\right)
$$

where $\Phi$ is the cumulative normal distribution function.

Table 3 contains the marginal effects implied by the parameter estimates from equation (2) and the P-values for a two-tailed t-test of significance on these parameters, and basic summary statistics from probit models estimated using data from the three surveys described above. This set of explanatory variables has been used to explain participation in gambling markets in a number of previous studies (Scott and Garen, 1994; Farrell and Walker, 1999; Worthington, 2001; Pérez and Humphreys, 2011).

Maximum likelihood estimators like probit do not generate the same diagnostic statistics as OLS. The usual OLS goodness-of-fit measure, $\mathrm{R}^{2}$ is not defined for the probit estimator. The pseudo- $\mathrm{R}^{2}$ values reporte don Table 3 are an approximation of the usual OLS goodness of fit measure, based on the estimated log-likelihood function from the probit regression model. They can be interpreted in the same way as $\mathrm{R}^{2}$.

Three consistent determinants of sports betting emerge from these results. First, males are more likely to bet on sports than females. The marginal effect varies quite a bit across the three countries, ranging from $4 \%$ in Canada to over $24 \%$ in Spain, but the evidence clearly suggests that men are more likely to bet on sports than women. Second, the likelihood that an individual bets on sports falls with age. Alternate probit models that included age squared were estimated in order to determine if the relationship between betting on sports and age was 
non-linear. The estimated parameters on the age squared variables were not statistically significant. Third, the likelihood that an individual bets on sports increases with income. Although the marginal effect is not large, this suggests that sports bettors tend to have somewhat higher incomes than people who do not bet on sports.

Table 3

Probit marginal effects - Participation in sports betting

\begin{tabular}{|l|c|c|c|c|c|c|}
\hline & \multicolumn{2}{c|}{ CANADA } & \multicolumn{2}{c|}{ SPAIN } & \multicolumn{2}{c|}{ UK } \\
\hline \multicolumn{1}{|c|}{ Variable } & Parameter & P-value & Parameter & P-value & Parameter & P-value \\
\hline Age & -0.001 & 0.001 & -0.004 & 0.001 & -0.001 & 0.001 \\
\hline Income & 0.0001 & 0.105 & 0.0021 & 0.027 & 0.0003 & 0.001 \\
\hline Male & 0.042 & 0.001 & 0.243 & 0.001 & 0.070 & 0.001 \\
\hline Single & -0.001 & 0.919 & -0.050 & 0.203 & 0.003 & 0.466 \\
\hline College & -0.003 & 0.304 & 0.017 & 0.441 & -0.013 & 0.001 \\
\hline Employed & 0.003 & 0.671 & 0.006 & 0.833 & 0.013 & 0.001 \\
\hline Number in Household & -0.013 & 0.168 & -0.001 & 0.910 & -0.004 & 0.001 \\
\hline Observations & 1,339 & & 2,425 & & 22,497 & \\
\hline pseudo-R & 0.155 & & 0.067 & & 0.080 & \\
\hline Log Likelihood & -172 & & $-1,568$ & & $-4,461$ & \\
\hline
\end{tabular}

Source: Own elaboration.

Marital status, employment status, and household size are not strongly associated with the tendency of individuals to bet on sports. The relationship between education and sports betting is mixed. In the UK, individuals who did not attend college are more likely to bet on sports, while the level of education is not associated with the likelihood that an individual bets on sports in Spain and Canada.

The general picture that emerges from the conditional analysis of participation in sports betting markets in Canada, Spain and the UK is that sports bettors tend to be younger males with relatively high income. These results hold in three different countries with legal and easy access to sports betting opportunities. The specific types of sports betting available differ as well, with more sports betting options available in the UK and fewer in Canada and Spain.

\section{DISCUSSION}

We motivated this paper with two types of proposed changes in the availability of sports betting opportunities: the creation of new sports betting opportunities where none previously existed and the elimination of all sports betting opportunities that have taken place recently in the US; and the proposed 
expansion of existing sports betting opportunities beyond the current system of state-sponsored monopoly sports betting currently in place in many EU countries, including Spain. In both cases, the welfare of sports bettors and government revenues generated from implicit or explicit taxation of sports betting will be affected by these changes in betting opportunities.

\subsection{Who will bet on sports if betting opportunities expand?}

Based on our analysis of the characteristics of sports bettors, annual participation in sports betting markets is low. Less than $5 \%$ of the survey respondents in Canada and the UK reported betting on sports in the past year. Although lifetime participation may be high, casual gamblers appear to bet on sports infrequently in the UK and Canada. In Spain, about 30\% of participants reported betting in football pools weekly or monthly, suggesting a significantly higher annual participation rate. In all three countries, participants were largely male, and the conditional analysis of participation indicates that participation declines with age. The average sports bettor in all three countries had household income at or above the median household income, and the conditional analysis of participation indicates that participation increases with income. Thus the typical sports bettor is a young male with relatively high income.

Although the annual participation rates in Canada and the UK are small, they are not zero. People in these three countries are interested in betting on sports, and we suppose the US to be quite similar to Canada and the UK in many respects. This implies that a similar number of people in the US would be interested in legally betting on sports, if available. These potential sports bettors are either not currently betting on sports, or are betting on sports illegally. So, providing these individuals with legal sports betting opportunities will be a Pareto improvement, making one group better off without harming any other group..

The expansion of sports betting opportunities in places like the US, where sport betting was not available, or in those without a specific regulation for some types of betting, as internet gambling, like Spain, may likely attract a similar type of individual: young males with relatively high incomes. This profile of sports bettors matches the characteristics of those sports fans who watch sports on television (Hammervold and Solberg, 2006) and attend live sporting events (Borland and Macdonald, 2003). The similar characteristics of sports spectators and sports bettors also suggest that there may be important complementarities in watching sports and betting on sports. 


\subsection{Who may be the winners and losers from expanded betting opportunities?}

The answer to this question varies in the US and the EU. Recall that sport betting opportunities are being made legal in the US, while in the EU the monopoly sport betting operations run by governments may be eliminated in favour of increased competition and specific regulations on internet gambling are being set.

In the US, legal sports betting may be offered where it was previously illegal. As was mentioned above, this opportunity is expected to increase the utility of individuals who would like to bet on sports but were unable to when sports betting was illegal. Since sport betting in Canada, and in the US state of Montana, features extremely high takeout rates or overround, the revenues generated from sports betting should be substantial, benefitting the government and, indirectly, those who receive government-provided benefits financed by the revenues generated from sports betting.

In addition, the government revenues generated from sport betting have two appealing features. First, revenues raised from sport betting constitute a "voluntary" tax in that no one is obligated to bet on sports. Second, the individuals who may likely participate in this activity have relatively high incomes, making this implicit tax both voluntary and progressive.

The most vocal opponents to legalized sport betting in the US were professional sports leagues like the NFL and amateur sports organizations like the NCAA. Since these organizations oppose the legalization of sport betting, they would appear to lose something following the legalization of sport betting. However, these losses are difficult to identify.

Opponents of legalized sport betting claim that the opportunity to bet on sports corrupts participants, including athletes and officials, by creating incentives to fix games and engage in other behaviour like point shaving that reduces the perceived legitimacy of the product. But game fixing and point shaving appear to be rare in North American team sports, based on past cases where participants engaged in game fixing or point shaving were caught and punished. National Basketball Association (NBA) referee Tim Donaghy reportedly gambled on games he officiated in the 2007 season. Prior to this, no allegations of game fixing related to gambling have been made in the four major professional sports leagues in North America in some time. College sports, on the other hand, periodically experiences episodes of game fixing. Examples of game fixing related to gambling in the NCAA include the University of Toledo (men's basketball and football 2003-2006), Northwestern University (men's basketball, 1995), Arizona State University (men's basketball, 1994), and Boston College (football, 1996;men's basketball, 1978). However, NCAA athletes receive no compensation beyond tuition and room and board, providing NCAA 
athletes with an incentive to engage in this behaviour. In addition, there are hundreds of Division I football and basketball programs in the US, compared to a few dozen professional teams in each league, providing many more opportunities for game fixing.

Also, good reasons exist to believe that the marginal effect of increased opportunities to bet on sport will not affect the incentive to fix games. Sport betting is already legal in Nevada, and internet betting with off-shore sports book is relatively easy, so any potential game fixer already has access to sports betting opportunities. In addition, the other existing sport betting opportunities in North America consist of "parlay" games where multiple contests must be bet on in each game. This clearly increases the cost of game fixing because players on multiple teams would have to be involved. The expansion of "parlay" type sports betting would appear to have only a limited effect on the incentive to fix games in North America.

Two groups would clearly lose from an expansion of sports betting opportunities in North America: illegal sports book makers and "offshore" internet sports books the currently operate in the Caribbean and Central American countries with liberal gambling laws. An expansion of legal sport betting opportunities in the US would reduce he handle at these locations, if the legal opportunities are substitutes for their betting options.

In Europe, as in the particular case of Spain, the winners and losers differ significantly. The clear losers will be the state-operated sport betting monopolies, and the groups who receive funding generated by the rents earned by these monopolies. The introduction of competition in European sport betting markets, either in the form of on-line sports books or UK style private betting shops will reduce the monopoly rents earned by state-operated monopolies. The revenues from state-sponsored sport betting monopolies in Europe typically go to professional leagues (the Spanish Professional Football League receives 10\% of football pool revenues - in 2005 this amounted to approximately $€ 50$ million), specific activities like the training of elite athletes or the operation of the European club sport system that trains young athletes and organizes competitions. These organizations will have to find new sources of funding if the rents generated from sport betting disappear. The equity and efficiency effects of this change are complex. To the extent that watching sport and betting on sport are complements, sports bettors are potentially a reasonable source of funds to subsidize the training of athletes and the organization of competitions. However, participation in sport may generate other important benefits to both the participants, in the form of enhanced earnings ability and to society in the form of a healthier and happier population. If these benefits are important, then alternative methods of financing the training of athletes and the organization of competitions may be desirable. 
The winners in Europe will clearly include both sports bettors and market regulators. Players will have access to a richer array of sports betting opportunities and will be subject to lower takeout rates and overround. Increased access to higher quality betting opportunities will increase the utility sports bettors get from betting and lower takeout rates and overround will reduce the effective cost of betting. In addition, the expansion of internet betting will reduce the transactions costs faced by sports bettors and might also shrink the illegal betting market in those countries. With regards to the Spanish case, the new gaming law includes a wide package of measures to protect consumers in general and children and gambling addicts in particular. In addiction, the Spanish gaming law bans operators to grant loans or any other type of financial assistance to people that want to gamble.In this respect, authorities will refuse to grant a license if there is a violation of law.

On the other hand, the expansion of betting opportunities may increase the potential value of the market, but without the appropriate regulatory framework this profits may be beyond the reach of the Spanish government. Thus, the appropriation of these revenues crucially depends on the establishment of an optimal taxation system. In Spain, individuals or companies which organise and develop the betting activities are the ones subject to the payment of the gambling taxes. The new Spanish gaming law set a new tax regime for those gambling activities regulated under the act, with tax rates of up to 25 percent depending on the type of game. With increased liberalization, Spain's betting market is expected to experience massive growth over the next years.

\section{REFERENCES}

BORLAND, J. AND MCDONALD, R. (2003). "Demand for sport". Oxford Review of Economic Policy, 19, pp. 478-502.

FARRELL, L. AND WALKER, I.(1999). "The welfare effects of lotto: evidence from the UK". Journal of Public Economics, 72, pp. 99-120.

FORREST, D. and SIMMONS, R. (2003). "Sport and gambling". Oxford Review of Economic Policy, 19, pp. 598-611.

GARCÍA, J. AND RODRÍGUEZ, P. (2007). "The Demand for football pools in Spain: The Role of price, prizes, and the composition of the coupon". Journal of Sports Economics, 8, pp. 335-354.

GARCÍA, J.; PÉREZ, L. AND RODRÍGUEZ, P. (2008). "Football pool sales: How important is a football club in the top division?". International Journal of Sport Finance, 3, pp. 167-176. 
HAMMERVOLD, R. AND SOLBERG, H. (2006). "TV sports programs - Who is willing to pay to watch?". Journal of Media Economics, 19, pp. 147-162.

PÉREZ, L. AND HUMPHREYS, B. (2011). "The income elasticity of lottery: New evidence from micro data". Public Finance Review, 39, pp. 551-570.

SAUER, R. (2001). "The political economy of gambling regulation". Managerial and Decision Economics, 22, pp. 1-15.

SCOTT, F. AND GAREN, J. (1994). "Probability of purchase, amount of purchase, and the demographic incidence of the lottery tax". Journal of Public Economics, 54, pp. 121-143.

SIMMONS, R. (2008). "Prohibition of gambling". In Medocroft, J. (ed.): Prohibitions (Readings in Economics). London: Institute of Economic Affairs.

STRUMPF, K. (2003). Illegal sports bookmakers. Unpublished working paper. Department of Economics. University of North Carolina at Chapel Hill.

WORTHINGTON, A. (2001). "Implicit finance in gambling expenditures: Australian evidence on socioeconomic and demographic tax incidence". Public Finance Review, 29, pp. 326-342. 
